\title{
Human Pharmacokinetics and Adverse Effects of Pulmonary and Intravenous THC-CBD Formulations
}

\author{
Pascale Meyer Manuela Langos Rudolf Brenneisen \\ Department of Clinical Research, University of Bern, Bern, Switzerland
}

\section{Keywords}

Delta-9-tetrahydrocannabinol - Cannabidiol · Phase-1 study . Inhalation · Injection · Pharmacokinetics · Adverse effects

\begin{abstract}
Background: Due to variable absorption and extensive firstpass metabolism, the bioavailability of oral delta-9-tetrahydrocannabinol (THC) and cannabidiol (CBD) is low, and, therefore, alternative application forms are necessary. Methods: In an open-label, 2-period phase-1 study on 11 healthy volunteers, a combination of THC and CBD was compared by pulmonary (inh) and intravenous (iv) application. The liquid aerosol was produced by an in vitro validated pressurized metered-dose inhaler (pMDI) device, releasing $41-44 \%$ of the cannabinoid dose, enabling a dosage of $81 \mu \mathrm{g} \mathrm{THC}$ and $87 \mu \mathrm{g}$ CBD per actuation. Three subjects (pilot trial, low-dose session) received 324 and $348 \mu$ THC and CBD, respectively, and 8 subjects (main trial, high-dose session) received 648 and $696 \mu \mathrm{g}$ THC and CBD, respectively. The addition of the local anesthetic lidocaine to the inh preparation should prevent airways irritation and coughing. The pharmacokinetic evaluation was based on plasma profiles acquired by gas
\end{abstract}

chromatography-mass spectrometry. Adverse effects were monitored by visual analog scales and measuring vital functions. Results: After low inh doses, THC and CBD were not measurable in plasma longer than 20 and 40 min after administration, respectively. Therefore, only plasma levels resulting after high doses were further evaluated. After inh and iv administration, THC plasma peaks were observed $5 \mathrm{~min}$ post-drug, with THC peak concentrations ranging from 3 to 22 and from 13 to $40 \mathrm{ng} / \mathrm{mL}$, respectively. CBD peaks were also measured 5 min after inh and iv administration, with concentrations ranging from 2 to 17 and from 14 to $26 \mathrm{ng} /$ $\mathrm{mL}$, respectively. The elimination half-lives were 7 and 11 min after inh and 22 and 24 min after iv administration for THC and CBD, respectively. The mean inh bioavailability (calculated vs. iv) was $55 \pm 37$ and $59 \pm 47 \%$ for THC and CBD, respectively. Conjugated 11-carboxy-THC was the main THC metabolite. The nebulized aerosol was generally well tolerated with little or no coughing and only slight psychological adverse effects. These were more distinct after iv administration, especially irritations and hallucinations. Besides moderate tachycardia, the vital functions stayed unchanged. Conclusions: We conclude that a THC-CBD inh aerosol shows favorable pharmacokinetic properties, which are similar to

\begin{tabular}{|c|c|}
\hline KARGER & $\begin{array}{l}\text { (c) } 2018 \text { The Author(s) } \\
\text { Published by S. Karger AG, Basel }\end{array}$ \\
\hline $\begin{array}{l}\text { E-Mail karger@karger.com } \\
\text { www.karger.com/mca }\end{array}$ & $\begin{array}{l}\text { This article is licensed under the Creative Commons Attribution- } \\
\text { NonCommercial-NoDerivatives } 4.0 \text { International License (CC BY- } \\
\text { NC-ND) (http://www.karger.com/Services/OpenAccessLicense). } \\
\text { Usage and distribution for commercial purposes as well as any dis- } \\
\text { tribution of modified material requires written permission. }\end{array}$ \\
\hline
\end{tabular}

Prof. Rudolf Brenneisen, $\mathrm{PhD}$

Swiss Task Force for Cannabinoids in Medicine (STCM) Frikartweg 9A

CH-3006 Bern (Switzerland)

E-Mail sacm@bluewin.ch 
those of an iv preparation. Adding a local anesthetic is recommended to prevent coughing, which decreases absorption. The negligible psychoactivity may be due to an antipsychotic effect of CBD, the low THC dosage, and/or the decreased formation of the psychoactive metabolite 11hydroxy-THC. Therefore, the inhalation via a pMDI is a viable, safe, and well-tolerated alternative to the oral administration.

(c) 2018 The Author(s)

Published by S. Karger AG, Basel

\section{Introduction}

Due to variable, erratic absorption and extensive first-pass metabolism, but also dependent on ingested food and type of oral formulation, the bioavailability of oral delta-9-tetrahydrocannabinol (THC) is low, with only $5-20 \%$ reaching the systemic circulation [1-3]. Thus, alternative application forms are necessary. The pulmonary delivery of drugs to treat systemic diseases has the advantage of reproducible absorption kinetics and is independent of dietary complications, extracellular enzymes, and inter-patient metabolic differences that affect gastrointestinal absorption [4]. In a previous study, the pharmacokinetics of THC were determined after pulmonary (inh) delivery of an aqueous aerosol nebulized by a pressure-driven device (Pari Master ${ }^{\circledR}$ ) and after intravenous (iv) injection [5]. The mean inh bioavailability was about $28 \pm 23 \%$, and the peak plasma concentration $\left(\mathrm{C}_{\max }\right)$ was already reached after $10 \mathrm{~min}$. The level of the metabolite 11-hydroxy-THC (11-OHTHC), which is known to be as psychoactive as THC, was lower after inh than after oral application [6]. The tolerability of the inh aerosol was good, but some coughing and irritation of the upper airways were seen, influencing the efficiency of the inhalation process and, thus, bioavailability. There is increasing evidence of the polypharmacological mechanisms of action and therapeutic potential of cannabidiol (CBD) [7-9]. For example, it shows anticonvulsive, antianxiolytic, antipsychotic, antiemetic, and antirheumatic effects. Some authors even claim the existence of a synergy or "entourage effect" between CBD and THC [8]. In this sense, a THC-CBD combination seems to be justified to optimize the therapeutic range. Consequently, a further study was carried out in which the pharmacokinetic properties and tolerance of inh THC-CBD were compared to an iv administration. The THC-CBD combination was applied in the form of an aerosol nebulized by a pressurized metered-dose inhaler (pMDI).

Pharmacokinetics and Adverse Effects of inh and iv THC-CBD Formulations

\section{Material and Methods}

\section{Chemicals}

THC, 11-OH-THC, 11-nor-9-carboxy-THC (11-COOHTHC), and CBD were provided by THC Pharm GmbH (Frankfurt a.M., Germany) and their deuterated standards by Lipomed (Arlesheim, Switzerland). Lidocaine hydrochloride (LC) Ph.Eur., bacterial $\beta$-glucuronidase (E. coli, type IX-A), and N,O-bis(trimethylsilyl)trifluoroacetamide containing $1 \%$ trimethylchlorosilane (BSTFA/TMCS) were obtained from Sigma-Aldrich Chemie (Buchs, Switzerland). All other chemicals and solvents were of the best available grade from Merck (Dr. Grogg Chemie, Bern, Switzerland) or Fluka Chemie (Buchs, Switzerland). The solid phase extraction columns (BakerBond SPE octadecyl cartridges) were purchased from Stehelin (Basel, Switzerland).

\section{Clinical Test Preparations}

All inh and iv solutions were prepared under good manufacturing practice conditions at the Institute of Hospital Pharmacy of the University Hospital of Bern. For the inh application of the inhalation solutions, a pMDI, consisting of a $10-\mathrm{mL}$ aluminium canister, a 50- $\mu \mathrm{L}$ valve (type C386, Bespak, UK), and an actuator (type 621, Bespak), was used. Hydrofluoroalkane (HFA 227) was functioning as a propellant and diluent. The particle size (mass median aerodynamic diameter) of THC and CBD emitted from the pMDI was determined by Copley impactor analysis. All inhaler parts were FDA approved.

\section{THC-CBD Inhalation Solutions}

THC-CBD inhalation solutions were prepared by filling a 10 $\mathrm{mL}$ aluminium canister (C1240, Presspart, UK) with $200 \mu \mathrm{L}$ of a stock solution of THC-CBD-ethanol 1:1:8 (w/w), $160 \mu \mathrm{L}$ of a solution of $2.5 \%$ glycerol in absolute ethanol, and $200 \mu \mathrm{L}$ of $20 \%(\mathrm{w} / \mathrm{v})$ $\mathrm{LC}$ in absolute ethanol. The canister was then fitted with a $50-\mu \mathrm{L}$ valve (type 357, Bespak) and gassed with HFA 227 propellant to a fill weight of $8,000 \mathrm{mg}$, equivalent to $5 \mathrm{~mL}$ of total fill volume. Therefore, each canister contained $20 \mathrm{mg}$ of THC, $20 \mathrm{mg}$ of CBD, and $40 \mathrm{mg}$ LC dissolved in a 5-mL solution and capable of delivering up to 100 actuations.

\section{Placebo Inhalation Solutions}

Placebo inhalation solutions were used to practice the inhalation procedure and were prepared by filling a $10-\mathrm{mL}$ aluminium canister with $200 \mu \mathrm{L}$ of absolute ethanol containing no test substances plus $160 \mu \mathrm{L}$ of a solution of $2.5 \%$ glycerol and $200 \mu \mathrm{L}$ of $20 \%(\mathrm{w} / \mathrm{v})$ LC in absolute ethanol.

THC-CBD Injection Solutions

THC-CBD injection solutions were prepared as for an earlier study [1]. The iv solutions contained $10 \mathrm{mg}$ THC, $10 \mathrm{mg} \mathrm{CBD,}$ $150.0 \mathrm{mg}$ polysorbate 80 (Tween 80 ), $10.0 \mathrm{mg}$ sodium ascorbate, $500 \mu \mathrm{L}$ absolute ethanol, and $0.9 \%$ sodium chloride, $\mathrm{pH} 7.4$, added up to $10.0 \mathrm{~mL}$. The iv solutions were freshly prepared and filtrated under sterile conditions after sonication for $30 \mathrm{~s}$.

\section{Clinical Study}

The clinical trial was conducted as a phase-1, open-label, single-center, 2-period study. Eleven healthy volunteers ( 5 females, 6 males; age 18-40 years, mean body weight $74 \mathrm{~kg}$ ), non-smokers, with normal lung functions (spirometry) and negative cannabis

Med Cannabis Cannabinoids 2018;1:36-43 
Fig. 1. Plasma levels of THC, its metabolites, and $\mathrm{CBD}$ after inh administration of a 1,600- $\mu \mathrm{g}$ THC-CBD inhalation solution. Main trial $(n=8)$. Values are means \pm SD. THC, delta-9-tetrahydrocannabinol; CBD, cannabidiol; inh, pulmonary; SD, standard deviation.



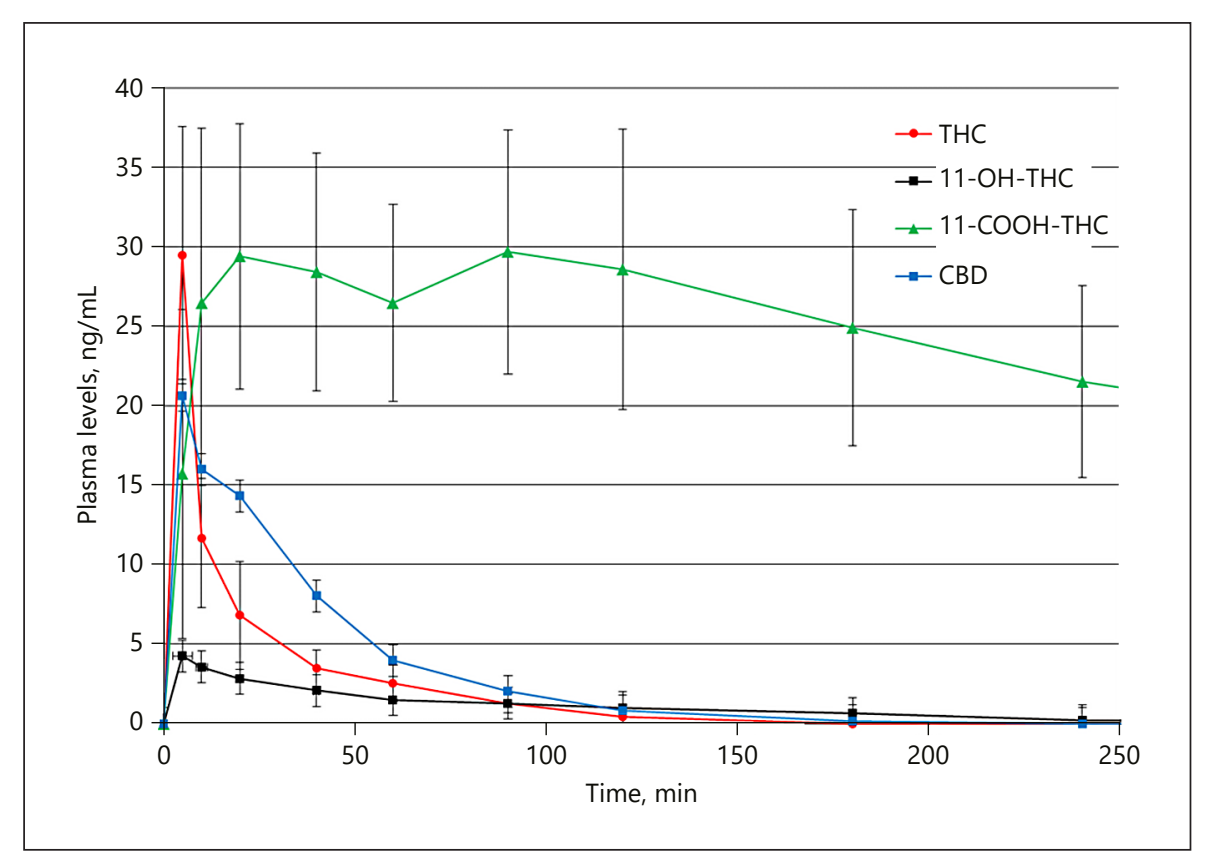

Fig. 2. Plasma levels of THC, its metabolites, and CBD after iv administration of a 1,600- $\mu \mathrm{g}$ THC-CBD injection solution. Main trial $(n=8)$. Values are means \pm SD. THC, delta-9-tetrahydrocannabinol; CBD, cannabidiol; SD, standard deviation. and pregnancy urine test before session start, were included. The subjects were recruited among coworkers of the Department of Clinical Research and the University Hospital of Bern or were medical students. The use of alcohol, any medication, or drugs within the last 2 days prior to and during the 1-day sessions was not allowed. Food was allowed until $12 \mathrm{~h}$ before trial start. All participants provided written informed consent and were under medical surveillance at the Clinical Investigation Unit of the University Hospital of Bern for $10 \mathrm{~h}$ after drug administration. The driving of vehicles and operating of machines during and $48 \mathrm{~h}$ after the trial was not allowed. The study was conducted according to GCP and ICH guidelines and considering the Declaration of Helsinki (Washington). It was approved by the Ethics Committee of the Canton of Bern (permit KEK-BE 59/05), by Swissmedic (ref. No. 2005 DR 1220), and by the Swiss Federal Office of Public Health.

\section{Inhalation Session}

Before the trials with the clinical test preparations, each subject had to practice the inhalation procedure by using the placebo inhalation solutions following the protocol exactly ( 1 shot into the 
Table 1. Pharmacokinetics of THC, THC metabolites, and CBD after inh and iv administration of a 1,600- $\mu \mathrm{g}$ THC-CBD inhalation and injection solution, respectively (main trial; $n=8$ )

\begin{tabular}{|c|c|c|c|c|c|c|c|c|}
\hline & \multicolumn{2}{|l|}{ Dose } & Analyte & \multicolumn{5}{|c|}{ Parameter } \\
\hline \multirow[t]{3}{*}{ Inhalation } & 1,600 & 648 & THC & 5 & 10 & 7 & 110 & 55 \\
\hline & & & 11-OH-THC & 11 & 1 & 216 & 33 & \\
\hline & & & 11-COOH-THC & 106 & 6 & 359 & 1,603 & \\
\hline \multirow[t]{4}{*}{ Injection } & 1,600 & 1,600 & THC & 5 & 30 & 22 & 542 & 100 \\
\hline & & & 11-OH-THC & 8 & 5 & 78 & 316 & \\
\hline & & & 11-COOH-THC & 53 & 34 & 229 & 10,343 & \\
\hline & 1,600 & 1,600 & $\mathrm{CBD}$ & 7 & 22 & 24 & 819 & 100 \\
\hline
\end{tabular}

Values are means. THC, delta-9-tetrahydrocannabinol; $C B D$, cannabidiol; inh, pulmonary; iv, intravenous; $t_{\text {max }}$, time to reach peak plasma concentrations; $C_{\max }$, peak plasma concentrations; $t_{1 / 2 z}$, elimination half-life; AUC, area under the concentration-time curve; $F$, bioavailability; 11-OH-THC, 11-hydroxy-THC; 11-COOH-THC, 11-nor-9-carboxy-THC.

spacer $\rightarrow$ inhale $\rightarrow$ hold for $10 \mathrm{~s} \rightarrow$ exhale; repeat 3 times). Every session was followed by a 1-week washout phase. In the pilot study, 3 subjects were included; 4 pMDI actuations were performed with nominal total doses of $800 \mu \mathrm{g}$ THC, $800 \mu \mathrm{g} \mathrm{CBD}$, and 1,600 $\mu \mathrm{g} \mathrm{LC}$, corresponding to total aerosol doses of 324 and $348 \mu \mathrm{g}$ THC and $\mathrm{CBD}$, respectively, based on a determined pMDI release performance of $41 \%$ THC and $44 \%$ CBD. In the main study, 8 subjects were included; 8 pMDI actuations were performed with nominal total doses of $1,600 \mu \mathrm{g}$ THC, 1,600 $\mu \mathrm{g}$ CBD, and 1,600 $\mu \mathrm{g} \mathrm{LC}$, corresponding to total aerosol doses of 648 and $696 \mu \mathrm{g}$ THC and CBD, respectively.

\section{Injection Session}

Pilot Study. Three subjects were included; $0.8 \mathrm{~mL}$ iv THC-CBD injection solution was administered, corresponding to $800 \mu \mathrm{g}$ THC and $800 \mu \mathrm{g}$ CBD.

Main Study. $1.6 \mathrm{~mL}$ iv THC-CBD injection solution was administered, corresponding to $1,600 \mu \mathrm{g}$ THC and 1,600 $\mu \mathrm{g} \mathrm{CBD}$.

Blood Sampling. 10-mL samples were collected by a peripheral vein catheter (Venflon ${ }^{\circledR}$ ) 15 min before baseline and 5, 10, 20, 40, $60,90,120,180,240$, and $480 \mathrm{~min}$ post-dosing. The samples were immediately centrifuged (1,500 r.c.f., $\left.10 \mathrm{~min}, 4^{\circ} \mathrm{C}\right)$ and the plasma then instantly deep-frozen at $-20^{\circ} \mathrm{C}$. Psychotropic and somatic adverse effects (sedation, euphoria, anxiety, nausea, vertigo, headache, irritation of airways, coughing, etc.) were measured by visual analog scales (VAS) with $0 \mathrm{~cm}(0 \%)$ on the $10-\mathrm{cm}$ VAS scale standing for "not at all" and $10 \mathrm{~cm}$ (100\%) for "very strong." Vital functions (pulse oximetry, blood pressure, and heart rate) were permanently measured by patient monitors.

\section{Bioassay}

Gas chromatography-mass spectrometry (GC/MS) was used for the determination of THC, 11-OH-THC, 11-COOH-THC, and $\mathrm{CBD}$ in plasma following a procedure published earlier [5]. Briefly, 0.5-mL plasma aliquots were enzymatically hydrolyzed to de-

Pharmacokinetics and Adverse Effects of inh and iv THC-CBD Formulations conjugate the analytes, extracted on solid-phase columns, and derivatized by silylation. The trimethylsilyl derivatives were separated on a DB-1 MS column (30 $\mathrm{m} \times 0.25 \mathrm{~mm}$ i.d., $0.25-\mu \mathrm{m}$ film, $\mathrm{He}$ $1.2 \mathrm{~mL} / \mathrm{min}$; oven $200^{\circ} \mathrm{C}$ [ $0.5 \mathrm{~min}$ ] to $280^{\circ}$ at $5^{\circ} / \mathrm{min}, 280^{\circ}$ [ $\left.5 \mathrm{~min}\right]$ ), detected by selected ion monitoring, and quantified versus deuterated standards. Validation according to ICH guidelines showed that the assay was linear, accurate, precise, and sensitive with a lower limit of quantitation of $0.3-1 \mathrm{ng} / \mathrm{mL}$.

\section{Pharmacokinetic Calculations}

Plasma concentrations versus time were used to calculate pharmacokinetic parameters, including $\mathrm{C}_{\max }$, time to reach peak plasma concentrations $\left(t_{\max }\right)$, area under the concentration-time curve (AUC), elimination half-life $\left(t_{1 / 2 z}\right)$, and bioavailability $(F)$. Based on a non-compartmental model, all pharmacokinetic parameters were assessed by use of standard calculation procedures performed by the TopFit version 2.0 computer software. The time corresponding to the last measurable concentration (AUC0-t) was calculated by numeric integration using the linear trapezoidal rule.

\section{Results and Discussion}

A 3-subjects low-dosage pilot trial preceding the main high-dosage trial was requested by the regulatory authorities to check the applicability of the pMDI and tolerability of the inh test preparations used as a THC-CBD-LC combination for the first time in a clinical study. THC iv injection solutions originally developed and validated in our lab have already been used successfully in several clinical studies [5, 10-14]. No technical problems and adverse effects (VAS) were observed following the stan- 


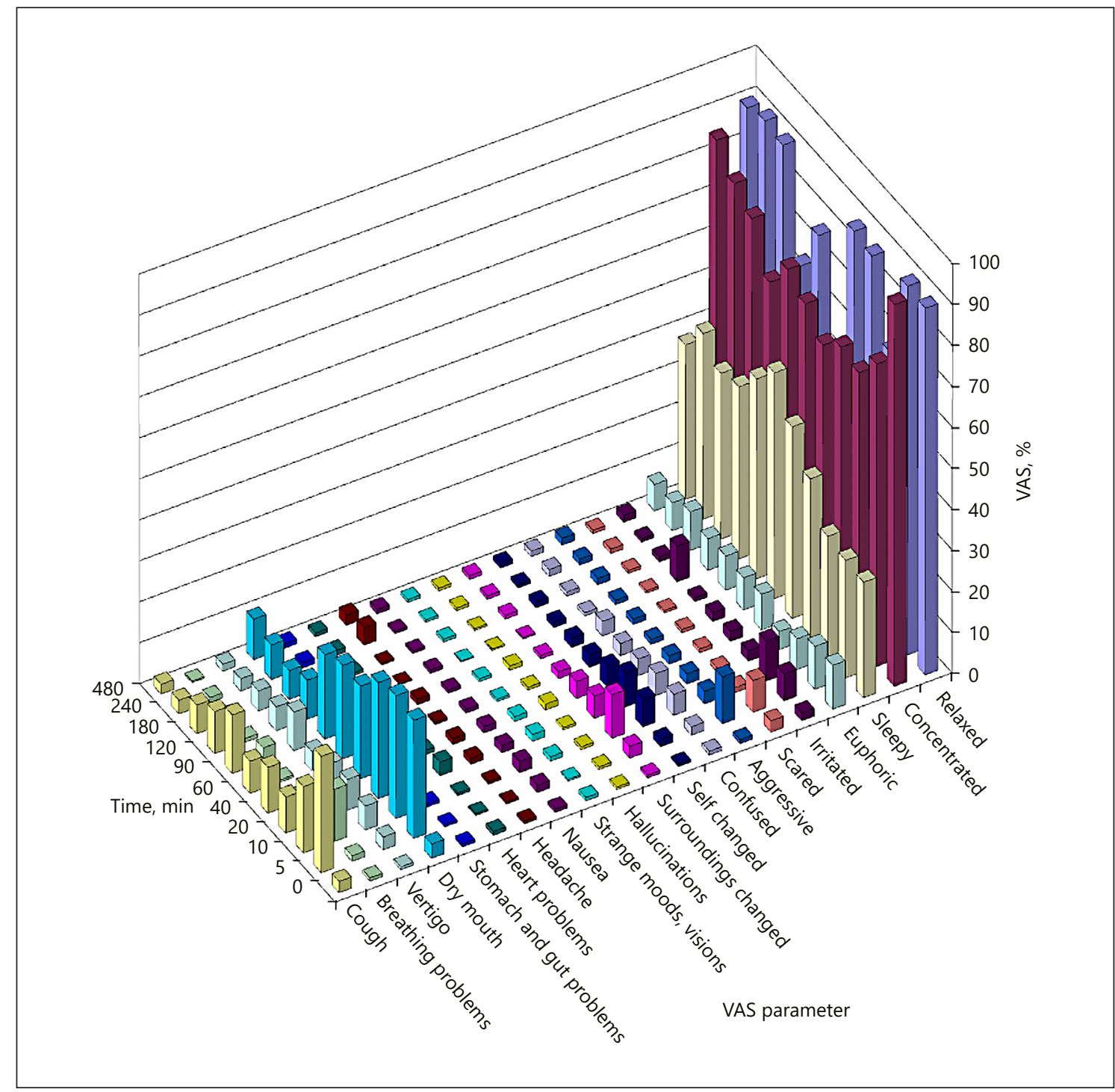

Fig. 3. Adverse effects monitored by VAS after inh administration of a 1,600- $\mu$ g THC-CBD inhalation solution. Main trial $(n=8)$. Values are means. VAS, visual analog scale; inh, pulmonary; THC, delta-9-tetrahydrocannabinol; CBD, cannabidiol.

dardized inhalation procedure and after a short training with placebo preparations. In addition, after nominal doses of $800 \mu \mathrm{g}$ THC and CBD, corresponding to released doses of $324 \mu \mathrm{g}(41 \%)$ and $348 \mu \mathrm{g}(44 \%)$, respectively, the plasma levels of the parent drugs dropped below the lower limit of quantitation of the bioassay (GC/MS) already after 20 and $40 \mathrm{~min}$, respectively. Therefore, it was decided to not further evaluate the data of the pilot session and proceed to the main trial with high dosages.

For the main high-dosage trial on 8 subjects, clinical inh and iv test preparations containing nominal doses of
1,600 $\mu \mathrm{g}$ THC and CBD, corresponding to pMDI-released aerosol doses of 648 and $696 \mu \mathrm{g}$, respectively, were administered. Figure 1 shows the plasma levels (means \pm standard deviations; $n=8$ ) of THC, its 2 main metabolites, and CBD after inh administration of a $1,600-\mu \mathrm{g}$ THC-CBD solution. $\mathrm{C}_{\max }$ of 10 (3-22) ng/mL and 7 (217) $\mathrm{ng} / \mathrm{mL}$ THC and CBD, respectively, were already observed at $5 \mathrm{~min}$, which demonstrates the rapid inh absorption. Noteworthy is that $\mathrm{t}_{\max }$ of inh THC and CBD are comparable to those after iv administration (Fig. 2). The THC metabolites 11-OH-THC and 11-COOH-THC 


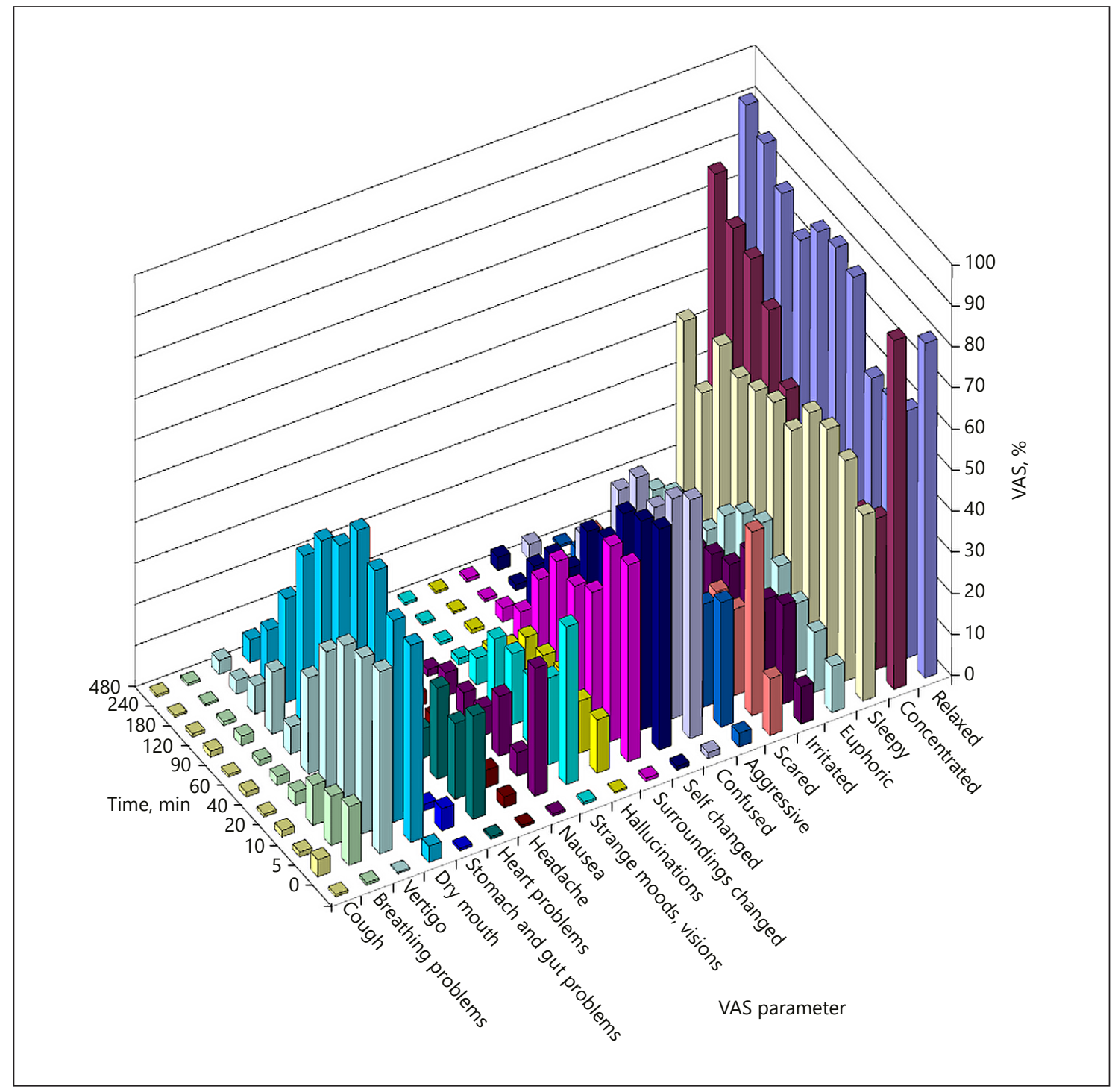

Fig. 4. Adverse effects monitored by VAS after iv administration of a 1,600- $\mu \mathrm{g}$ THC-CBD injection solution. Main trial $(n=8)$. Values are means. VAS, visual analog scale; THC, delta-9-tetrahydrocannabinol; CBD, cannabidiol.

peak at 11 and $106 \mathrm{~min}$ after inhalation, and 8 and $53 \mathrm{~min}$ after injection, respectively. Inh THC and CBD were not detectable 90 and 120 min after administration, respectively, whereas after iv administration, the levels were below the bioassay sensitivity after $180 \mathrm{~min}$. The approximate half-lives $t_{1 / 2 z}$ of THC and CBD were 7 and $11 \mathrm{~min}$ after inh and 22 and 24 min after iv administration, respectively. 11-OH-THC, which is also psychoactive, was no longer detectable $240 \mathrm{~min}$ after inhalation. The longterm and main urinary THC metabolite 11-COOH-THC persisted until the last blood collection time point, with
2.08 and $12.51 \mathrm{ng} / \mathrm{mL}$ at $480 \mathrm{~min}$ after inh and iv, respectively. The inh bioavailability F of inh THC ( $55 \pm 37 \%)$ was increased by a factor of 2 compared to an earlier study [5], where another nebulizer device (Pari Master ${ }^{\circledR}$ ) was used. In addition, with 1-2 $\mu \mathrm{m}$, the particle size (mass median aerodynamic diameter) of the THC-CBD aerosol emitted from the pMDI was smaller than the one resulting from the Pari Master ${ }^{\circledR}(3.8 \mu \mathrm{m})$. Particles $1-5 \mu \mathrm{m}$ in diameter are deposited in the small airways and alveoli with $>50 \%$ of the $3-\mu \mathrm{m}$-diameter particles being deposited in the alveolar region [15]. Particles $<3 \mu \mathrm{m}$ have an 
approximately $80 \%$ chance of reaching the lower airways with $50-60 \%$ being deposited in the alveoli $[16,17]$. After oral application, $\mathrm{F}$ is only $5-20 \%$, mainly due to an extensive first-pass metabolism [1-3]. With F being $59 \pm 47 \%$, also more than half of the nebulized CBD aerosol dose reached the systemic circulation. The pharmacokinetic characteristics of THC, its metabolites, and CBD after inh and iv administration are summarized in Table 1.

Figures 3 and 4 show the adverse effects after high doses $(1,600-\mu \mathrm{g}$ nominal, main trial; data for low-dosage pilot trial not shown) of inh and iv THC-CBD. Twenty psychological and somatic parameters were monitored by VAS at the same 11 time points as for blood sampling (0-480 $\mathrm{min})$. Most prominent for both application forms and over the whole observation period were the psychological parameters "relaxed," "concentrated," and "sleepy," adverse effects which were not experienced as unpleasant by most of the subjects. More disturbing were psychotropic effects, such as "scared," "confused," and "self or surroundings changed," which are quite typical for THC. These were minor or almost missing after inhalation. In an earlier study [1], where we compared pharmacokinetics and adverse effects of inh versus iv THC, the central side effects were much more intensive. The question whether this phenomenon is due to the postulated antipsychotic effect of CBD or different types of inhalers and dosages used cannot finally be answered. A conclusive interpretation would require standardized experimental conditions, i.e., a study comparing identical doses of inh and iv THC alone versus THC-CBD and applying the pMDI described in the present study. As represented by the VAS parameters "coughing" and "breathing problems," these earlier observed irritating effects of THC on the respiratory tract could significantly be reduced by addition of LC to the inhalation solution. The vegetative side effect "dry mouth" is also quite typical for
THC. The full bioavailability of iv THC-CBD explains the more prominent somatic symptoms, such as "stomach and gut problems" and "heart problems," as well as more pronounced psychological adverse effects, such as "irritated," "scared," or "confused." Besides moderate tachycardia, the vital functions stayed unchanged.

\section{Conclusions}

The pulmonary delivery of aerosolized THC-CBD solutions shows favorable pharmacokinetic properties, which are similar to those of an iv injection preparation. Adding a local anesthetic is recommended to prevent airways irritation and coughing, thus reducing inh bioavailability. The negligible psychoactivity may result from the antipsychotic CBD, the low THC dosage, and/or the decreased formation of the psychoactive metabolite 11-OHTHC. Therefore, the inhalation via $\mathrm{pMDI}$ is an alternative to the oral administration route and an option for reliable and safe application of medical cannabinoids.

\section{Acknowledgements}

The authors thank Andrew Davis, STI Pharmaceuticals Ltd. (Brentwood, UK), and Christian Steup, THC Pharm (Frankfurt a.M., Germany), for supporting the clinical study and assisting in validating in vitro the pMDI devices and inhalation solutions. Many thanks also to the staff of the Clinical Investigation Unit of the University Hospital of Bern, especially Dr. Haithem Chtioui for assisting in recruiting the subjects and medical surveillance of the sessions.

\section{Disclosure Statement}

The authors declare no conflicts of interest.

\section{References}

1 Wall ME, Sadler BM, Brine D, Taylor H, Perez-Reyes M: Metabolism, disposition, and kinetics of delta-9-tetrahydrocannabinol in men and women. Clin Pharmacol Ther 1983; 34:352-363.

2 McGilveray IJ: Pharmacokinetics of cannabinoids. Pain Res Manag 2005;10(suppl A): $15 \mathrm{~A}-22 \mathrm{~A}$

3 Marinol $^{\circledR}$ (dronabinol) capsules (package insert). North Chicago, IL, AbbVie, Inc., 2015.

4 Byron PR, Patton JS: Drug delivery via the respiratory tract. J Aerosol Med 1994;7:49-75.
5 Naef M, Russmann S, Petersen-Felix S, Brenneisen R: Development and pharmacokinetic characterization of pulmonal and intravenous delta-9-tetrahydrocannabinol (THC) in humans. J Pharm Sci 2004;93:1176-1184.

6 Naef M, Curatolo M, Petersen-Felix S, Arendt-Nielsen L, Zbinden A, Brenneisen R: The analgesic effect of oral delta-9-tetrahydrocannabinol (THC), morphine, and a THC-morphine combination in healthy subjects under experimental pain conditions. Pain 2003;105:79-88.
7 Mechoulam R, Peters M, Murillo-Rodriguez, Hanus LO: Cannabidiol - recent advances. Chem Biodivers 2007;4:1678-1692.

8 Pisanti S, Malfitano AM, Ciaglia E, Lamberti A, Ranieri R, Cuomo G, Abate M, Faggiana G, Proto MC, Fiore D, Laezza C, Bifulco M: Cannabidiol: state of the art and new challenges for therapeutic applications. Pharmacol Ther 2017;175:133-150.

9 Szaflarski JP, Bebin EM: Cannabis, cannabidiol, and epilepsy - from receptors to clinical response. Epilepsy Behav 2014;41:277-282. 
10 Morrison PD, Nottage J, Stone JW, Bhattacharyya S, Tunstall N, Brenneisen R, Holt D, Wilson D, Sumich A, McGuire P, Murray RM, Kapur S, Ffytche D: Disruption of frontal theta coherence by $\Delta^{9}$-tetrahydrocannabinol is associated with positive psychotic symptoms. Neuropsychopharmacology 2011;36: 827-836.

11 Barkus E, Morrison PD, Vuletic D, Dickson J, Ell PJ, Pilowsky LS, Brenneisen R., Holt DW, Powell J, Kapur S, Murray RM: Does intravenous delta-9-tetrahydrocannabinol increase dopamine release? A SPET study. J Psychopharmacol 2010;25:1462-1468.
12 Englund A, Morrison PD, Nottag J, Hague D, Kane F, Bonaccorso S, Stone JM, Reichenberg A, Brenneisen R, Holt D, Feilding A, Walker L, Murray RM, Kapur S: Cannabidiol inhibits THC-elicited paranoid symptoms and hippocampal-dependent memory impairment. J Psychopharmacol 2013;27:19-27.

13 Freeman D, Dunn G, Murray RM, Evans N, Lister R, Antley A, Slater M, Godlewska B, Cornish R, Williams J, Di Simplicio M, Igoumenou A, Brenneisen R, Tunbridge EM, Harrison P, Harmer CJ, Cowen P, Morrison PD: How cannabis causes paranoia: using the intravenous administration of $\Delta 9$-tetrahydrocannabinol (THC) to identify the key cognitive mechanisms leading to paranoia. Schizophr Bull 2015;41:391-399.

14 Kleine-Brueggeney M, Greif R, Brenneisen R, Urwyler N, Stueber, Theiler LG: Intravenous delta-9-tetrahydrocannabinol to prevent postoperative nausea and vomiting: a randomized controlled trial. Anesth Analg 2015; 121:1157-1164.
15 Labiris NR, Dolovich MB: Pulmonary drug delivery. Part I: physiological factors affecting therapeutic effectiveness of aerosolized medications. Br J Clin Pharmacol 2003;56:588599

16 Patton JS: Mechanisms of macromolecule absorption by the lungs. Adv Drug Deliv Rev 1996;19:3-36.

17 Folkesson HG, Westrom BR, Karlsson BW: Permeability of the respiratory tract to different-sized macromolecules after intratracheal instillation in young and adult rats. Acta Physiol Scand 1990;139:347-354. 